Supporting Information

\title{
Adsorptive Removal of Industrial Dye by Nanoporous Zr porphyrinic Metal-Organic Framework Microcubes
}

Eunji Jin, Jiyeon Kim, Joohan Nam, D. ChangMo Yang, Hyein Jeong, Seonghoon Kim, Eunyoung Kang, Hye Jin Cho and Wonyoung Choe*

Department of Chemistry, Ulsan National Institute of Science and Technology, 50 UNIST, Ulsan 44919, Republic of Korea

*E-mail: choe@unist.ac.kr 


\section{Experimental section}

\subsection{Materials and Methods}

Synthesis of PCN-224. PCN-224 was prepared according to the modified synthetic procedure. ${ }^{1-3} \mathrm{ZrOCl}_{2} \cdot 8 \mathrm{H}_{2} \mathrm{O}(125 \mathrm{mg}, 0.39 \mathrm{mmol})$ was dissolved in DMF (50 mL) in $100 \mathrm{~mL}$ vial. TCPP (25 mg, $0.032 \mathrm{mmol})$ and acetic acid $(12.5 \mathrm{~mL})$ were added to the solution and dissolved through sonication. The mixture was divided into 4 vials of $16 \mathrm{~mL}$ and heated to $65^{\circ} \mathrm{C}$ for $72 \mathrm{hrs}$, followed by cooling over $3 \mathrm{hrs}$. The purple powder crystals were obtained in the vial after the reaction. The yield is $\sim 330 \mathrm{mg}$. The samples were washed with fresh DMF and acetone for 4 days and dried under vacuum at $100{ }^{\circ} \mathrm{C}$ for $24 \mathrm{hrs}$.

Digestion. Digestion of PCN-224 structures is followed by a method using CsF. ${ }^{4}$ The CsF solution was produced that $24 \mathrm{mg}$ of CsF was dissolved in $450 \mu \mathrm{L}$ of DMSO-d 6 and $250 \mu \mathrm{L}$ of $\mathrm{D}_{2} \mathrm{O}$. Dried samples were digested using CsF solution, and the mixture was sonicated for 10 $\min$

\subsection{Adsorption Experiments}

The adsorption amount and the adsorption capacity were calculated using absorbance. The dilution of high concentration is a very critical portion because it affects the calculated adsorption amount and capacity.

The adsorption amount $\left(q_{t}, \mathrm{mg} \mathrm{g}^{-1}\right)$ at the time $(t, \mathrm{~min})$ was calculated as follow:

$$
q_{t}=\frac{\left(C_{0}-C_{t}\right) V}{m}
$$


$C_{0}\left(\mathrm{mg} \mathrm{L}^{-1}\right)$ is the initial concentration, $C_{t}\left(\mathrm{mg} \mathrm{L}^{-1}\right)$ is the concentration at the time, $V(\mathrm{~L})$ is the volume of the dye solution, $m(\mathrm{~g})$ is the mass of Zr-porphyrinic MOFs. $C_{t}$ was calculated by comparing the absorbance of the initial concentration and the concentration at the time.

The adsorption capacity $\left(q_{e}, \mathrm{mg} \mathrm{g}^{-1}\right)$ at equilibrium was calculated as follows:

$$
q_{e}=\frac{\left(C_{0}-C_{e}\right) V}{m}
$$

$C_{e}\left(\mathrm{mg} \mathrm{L}^{-1}\right)$ is the dye concentration at equilibrium. $C_{e}$ was calculated by comparing the absorbance of initial concentration and the concentration at equilibrium time. These values were used to calculate the adsorption kinetics and the adsorption isotherm.

\subsubsection{Adsorption kinetics}

Data for adsorption amounts at time $t$ are analyzed through the data fitting methods. After data fitting, the most feasible kinetic model is presented for each initial concentration via a comparison of $R^{2}$ value.

\section{Pseudo-first-order kinetics ${ }^{5}$}

$$
\log \left(q_{e}-q_{t}\right)=\log \left(q_{e}\right)-\frac{k_{1}}{2.303} t
$$

where $q_{e}\left(\mathrm{mg} \mathrm{g}^{-1}\right)$ is the adsorption capacity, $q_{t}\left(\mathrm{mg} \mathrm{g}^{-1}\right)$ is the adsorption amount at time $t$, $k_{1}\left(\min ^{-1}\right)$ is the pseudo-first-order rate constant. After linear regression of $\log \left(q_{e}-q_{t}\right)$ for $t, k_{1}$ is obtained from the slope and theoretical $q_{e}$ is obtained from the intercept.

\section{Pseudo-second-order kinetics ${ }^{6}$}

$$
\frac{t}{q_{t}}=\frac{1}{k_{2} q_{e}^{2}}+\frac{1}{q_{e}} t
$$


where $q_{e}\left(\mathrm{mg} \mathrm{g}^{-1}\right)$ is the adsorption capacity, $q_{t}\left(\mathrm{mg} \mathrm{g}^{-1}\right)$ is the adsorption amount at time $t$, $k_{2}\left(\mathrm{~g} \mathrm{mg}^{-1} \mathrm{~min}^{-1}\right)$ is the pseudo-second-order rate constant. After linear regression of $\frac{t}{q_{t}}$ for $t$, $k_{2}$ is obtained from the intercept and $q_{e}$ is obtained from the slope.

\subsubsection{Adsorption isotherms and capacity}

\section{Langmuir isotherm ${ }^{7}$}

$$
\frac{C_{e}}{q_{e}}=\frac{1}{Q K_{L}}+\frac{C_{e}}{Q}
$$

where $C_{e}\left(\mathrm{mg} \mathrm{L}^{-1}\right)$ is the dye concentration at equilibrium, $q_{e}\left(\mathrm{mg} \mathrm{g}^{-1}\right)$ is the adsorption capacity at equilibrium, $Q\left(\mathrm{mg} \mathrm{g}^{-1}\right)$ is the maximum adsorption capacity, and $K_{L}\left(\mathrm{~L} \mathrm{mg}^{-1}\right)$ is the Langmuir constant. The Langmuir model is fitted when a molecule is adsorbed onto the solid adsorbents, in an aqueous solution. The model presents that the surface of the adsorbent is uniform, and adsorbate should be attached as a monolayer. If the model is favorable, the separation factor $\mathrm{R}_{\mathrm{L}}$ should be $0<R_{L}<1$. The equation of $R_{L}$ is as below:

$$
R_{L}=\frac{1}{1+K_{L} C_{0}}
$$

Where $C_{0}\left(\mathrm{mg} \mathrm{L}^{-1}\right)$ is the initial concentration of the dye, and $K_{L}\left(\mathrm{~L} \mathrm{mg}^{-1}\right)$ is the Langmuir constant. In this equation, $R_{L}$ is dimensionless.

\section{Freundlich isotherm ${ }^{8}$}

$$
\ln \left(q_{e}\right)=\ln \left(K_{F}\right)+\frac{1}{n} \ln \left(C_{e}\right)
$$


where $C_{e}\left(\mathrm{mg} \mathrm{L}^{-1}\right)$ is the dye concentration at equilibrium, $q_{e}\left(\mathrm{mg} \mathrm{g}^{-1}\right)$ is the adsorption capacity at equilibrium, $K_{F}\left(\mathrm{mg} \mathrm{g}^{-1}\right)$ is the Freundlich constant, and $n$ is the heterogeneity factor. The Freundlich model is well-matched when the adsorbent has a heterogeneous surface.

\subsubsection{Intraparticle diffusion model ${ }^{9}$}

$$
q_{t}=k_{i} t^{0.5}+I
$$

where $q_{t}\left(\mathrm{mg} \mathrm{g}^{-1}\right)$ is the adsorption capacity at time $t, k_{i}\left(\mathrm{mg} \mathrm{g}^{-1} \mathrm{~h}^{-0.5}\right)$ is the intraparticle diffusion constant and $I\left(\mathrm{mg} \mathrm{g}^{-1}\right)$ is the coefficient associated with the thickness of the boundary layer. This model elucidates the effects of intraparticle diffusion on the adsorption rates.

\subsection{Computational details}

The adsorption energies were calculated with the density functional theory (DFT) method in two stages. ${ }^{10}$ The first is to optimize the spatially periodic structure of $\mathrm{PCN}-224\left(\mathrm{H}_{2}\right)$ by constructing the orbitals of atoms in a unit cell with the plane-wave basis set. The Vienna Ab initio Simulation Package (VASP) $)^{11,12}$ is one of several production-level implementations of DFT in this way, which we have used for this step with the plane-wave kinetic energy cutoff at $400 \mathrm{eV}$ and a $\Gamma$-point sampling of the Brillouin zone. The settings were enough for having the total energy of the cell converge to within $5 \mathrm{meV}$ per atom (about $0.5 \mathrm{~kJ} / \mathrm{mol}$ per atom). The electrons and nuclei interact with the projector-augmented wave potentials. ${ }^{13}$ We used the energy functional of the Perdew-Becke-Ernzerhof (PBE) form ${ }^{14,15}$, added with Grimme's D3 dispersion correction ${ }^{16}$ and Becke-Johnson (BJ) damping ${ }^{17-20}$. By specifying the locations of all of the $\mathrm{H}$ atoms, the space group of the unit cell is lowered from $\operatorname{Im} \overline{3} m$ to a generic bodycentered cubic structure. An energy convergence condition of $10^{-4} \mathrm{eV}$ was used for each self- 
consistent field step and a force convergence condition of $0.02 \mathrm{eV} / \AA$ for the relaxation of the nuclei.

Once the periodic structure is optimized, the second step is to cut out the $\mathrm{Zr}_{6}$ nodes and porphyrin linkers as separate entities. For the node, the cut is made at the $\mathrm{C}$ atoms just past the nearest 6 aryl rings with $\mathrm{H}$ atoms added to fill the electron shells. For the linker, the cut is made at the $\mathrm{O}$ atom pairs, without adding any $\mathrm{H}$ atoms. These structures are attached as $\mathrm{XYZ}$ files. Removed from the spatially periodic setting, they are treated as molecular fragments along with the dye molecule. Their electron orbitals are constructed with localized basis sets, which in our study is def2-SVP ${ }^{21}$ for atoms up to $\mathrm{S}$ and $\mathrm{SDD}^{22}$ for $\mathrm{Zr}$. The latter describes only the valence electrons and is supplied with an associated effective core potential. For a package specialized for these localized basis sets, we used Gaussian $16 .{ }^{23}$ DFT calculations here are done with the same settings as the previous stage, PBE-D3(BJ), but this time in the polarizable continuum model (PCM) to incorporate the effect of water as the implicit solvent. ${ }^{24}$ Gaussian 16, in particular, does not support automatic correction for the basis set superposition errors between the molecular fragments $\left(\mathrm{Zr}_{6}\right.$ node and the dye molecule) when any implicit solvent model is enabled, so the counterpoise correction is made for the system with the same adsorption geometry in the implicit solvent model, but only having the implicit solvent switched off. To mimic the surrounding MOF structure, the carbon atoms of the aryl rings were held fixed while the other atoms were allowed to relax. 


\section{Adsorptive removal for an azo dye}

Table S1. Characterization of methyl orange as an azo dye.

\begin{tabular}{c}
\hline Organic dye \\
Methyl Orange \\
Nature \\
pKa \\
$\lambda_{\text {max }}\left(\mathrm{nm}^{2}\right)$ \\
Size (nm $\left.{ }^{3}\right)$ \\
Solubility $\left(\mathrm{g} \mathrm{L}^{-1}\right)$ \\
MW (g mol $\left.{ }^{-1}\right)$
\end{tabular}



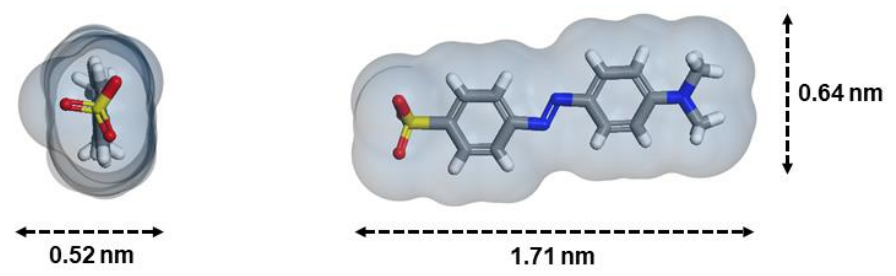

b
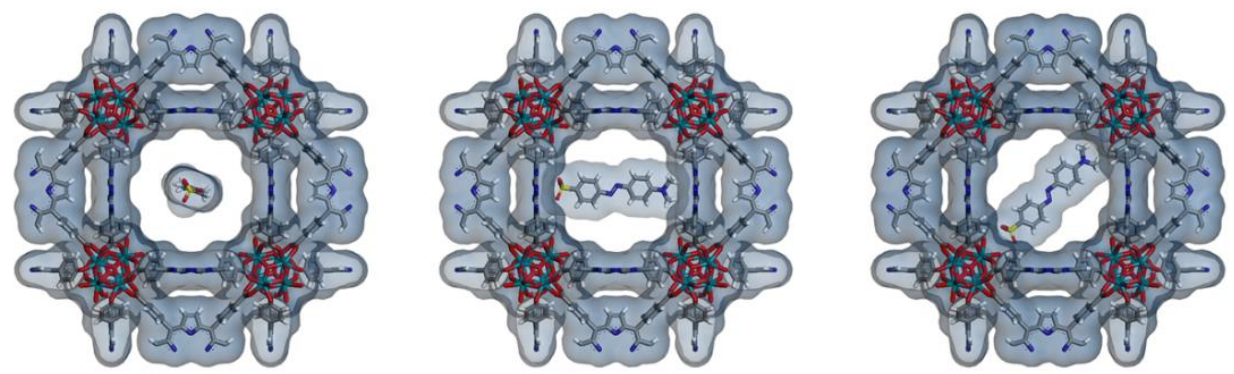

Figure S1. Connolly surface of (a) MO molecule and (b) MO@PCN-224 with $1.4 \AA$ vdW radius using Material Studio. An illustration of three orientations of MO molecule, located at pore aperture of PCN224. 


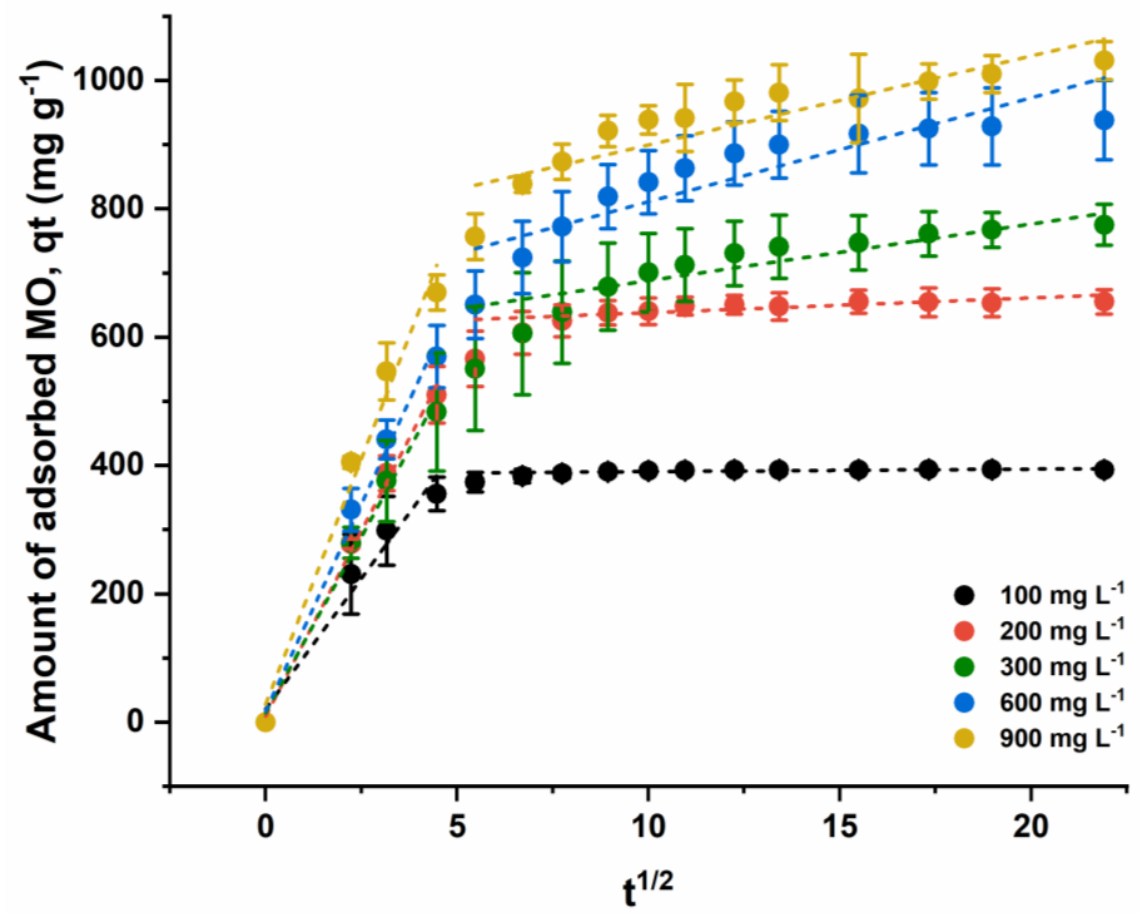

Figure S2. Intraparticle diffusion model for five initial concentrations onto PCN-224. 
Table S2. Intraparticle diffusion model of MO adsorption onto PCN-224.

\begin{tabular}{ccccccc}
\hline $\begin{array}{c}\text { Init. Conc. } \\
\left(\mathbf{m g ~ \mathbf { L } ^ { - 1 }}\right)\end{array}$ & $\mathbf{k}$ & Region 1 & \multicolumn{3}{c}{ Region 2 } \\
\cline { 2 - 7 } & $\mathbf{\text { intercept }}$ & $\mathbf{R}^{\mathbf{2}}$ & $\mathbf{k}$ & intercept & $\mathbf{R}^{\mathbf{2}}$ \\
\hline 100 & 81.44 & 20.17 & 0.94954 & 0.3958 & 386.5 & 0.33002 \\
200 & 115.3 & 9.315 & 0.99346 & 2.305 & 615.0 & 0.38450 \\
300 & 109.5 & 14.59 & 0.98498 & 8.829 & 599.7 & 0.76684 \\
600 & 128.8 & 17.38 & 0.98510 & 16.20 & 649.0 & 0.75158 \\
900 & 152.9 & 27.89 & 0.97017 & 13.87 & 760.6 & 0.82444 \\
\hline
\end{tabular}




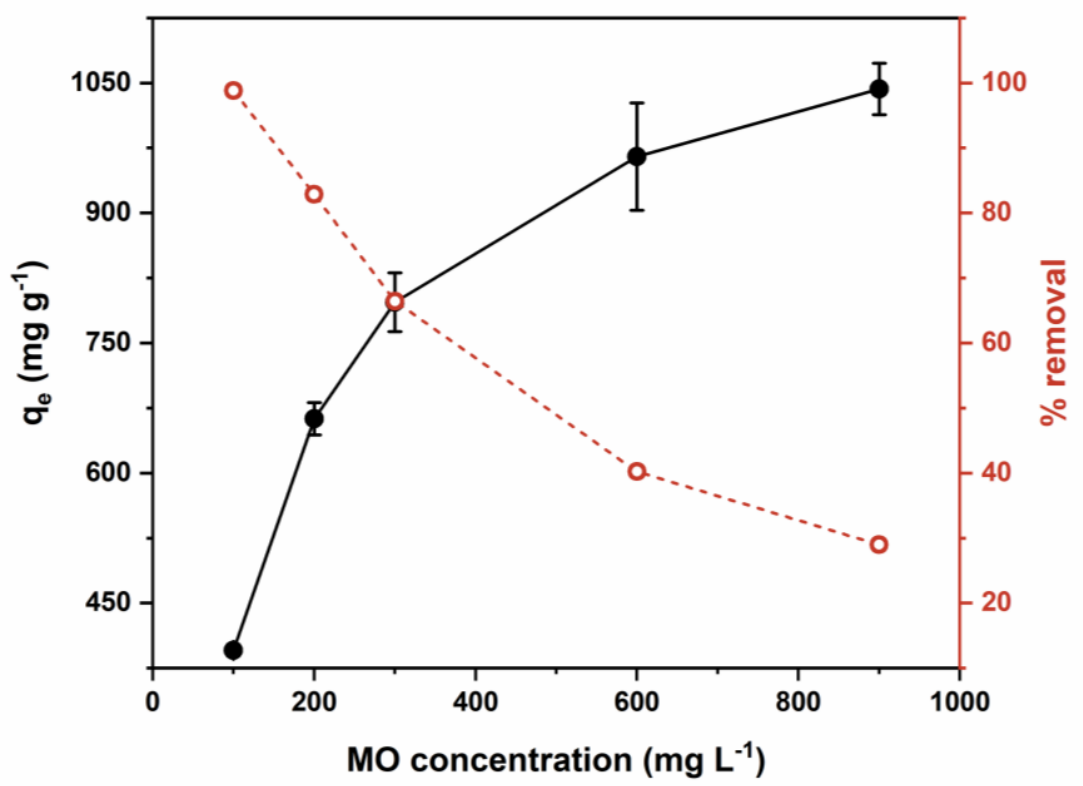

Figure S3. Cumulative removal of PCN-224 at different initial concentrations of MO. 
Table S3. The adsorption capacity of reported MOFs toward MO.

\begin{tabular}{|c|c|c|c|c|}
\hline MOF & $\begin{array}{l}q_{\mathrm{e}} \text { or } Q \\
(\mathrm{mg} / \mathrm{g})\end{array}$ & $\begin{array}{c}\text { Initial concentration } \\
(\mathbf{p p m})\end{array}$ & pH & Ref \\
\hline $\mathrm{PCN}-224$ & $1043(30)$ & 900 & Natural & This work \\
\hline MIL-100(Fe) & 484 & 900 & Natural & This work \\
\hline MOF2 & 102 & 5 & Natural & 28 \\
\hline UiO-66 & 173 & 500 & Natural & 29 \\
\hline MIL-53 & 58 & 50 & 5.6 & 30 \\
\hline MIL-101 & 92 & 50 & 5.6 & 30 \\
\hline ED-MIL-101 & 130 & 50 & 5.6 & 30 \\
\hline PED-MIL-101 & 180 & 50 & 5.6 & 30 \\
\hline MIL-100(Fe) & 1045 & 1000 & 5 & 27 \\
\hline MIL-100(Cr) & 212 & 1000 & 5 & 27 \\
\hline MIL-101-B 0 & 247 & 300 & Natural & 31 \\
\hline PCN-222 & 592 & 1000 & 5 & 25 \\
\hline $\mathrm{PCN}-222(\mathrm{Fe})$ & 380 & 400 & 5 & 26 \\
\hline MOF-235 & 477 & 200 & 5.6 & 32 \\
\hline Ce(III)-doped UiO-66 & 640 & 500 & 7 & 33 \\
\hline $\mathrm{Ce}(\mathrm{III})$-doped UiO-67 & 401 & 500 & 7 & 34 \\
\hline MIL-68(Al) & 341 & $100(308 \mathrm{~K})$ & 8 & 35 \\
\hline Amino-MIL-101(Al) & $189(9)$ & $40\left(30^{\circ} \mathrm{C}\right)$ & Natural & 36 \\
\hline $\begin{array}{l}\text { Fe-loaded MOF- } \\
545(\mathrm{Fe})\end{array}$ & 804 & 10 & 5 & 37 \\
\hline SCNU-Z4 & 95 & 25 & Natural & 38 \\
\hline MFC-O & 219 & 45 & 3 & 39 \\
\hline UiO-66- $\mathrm{NH}_{2}$ & 148 & 700 & 5 & 40 \\
\hline
\end{tabular}



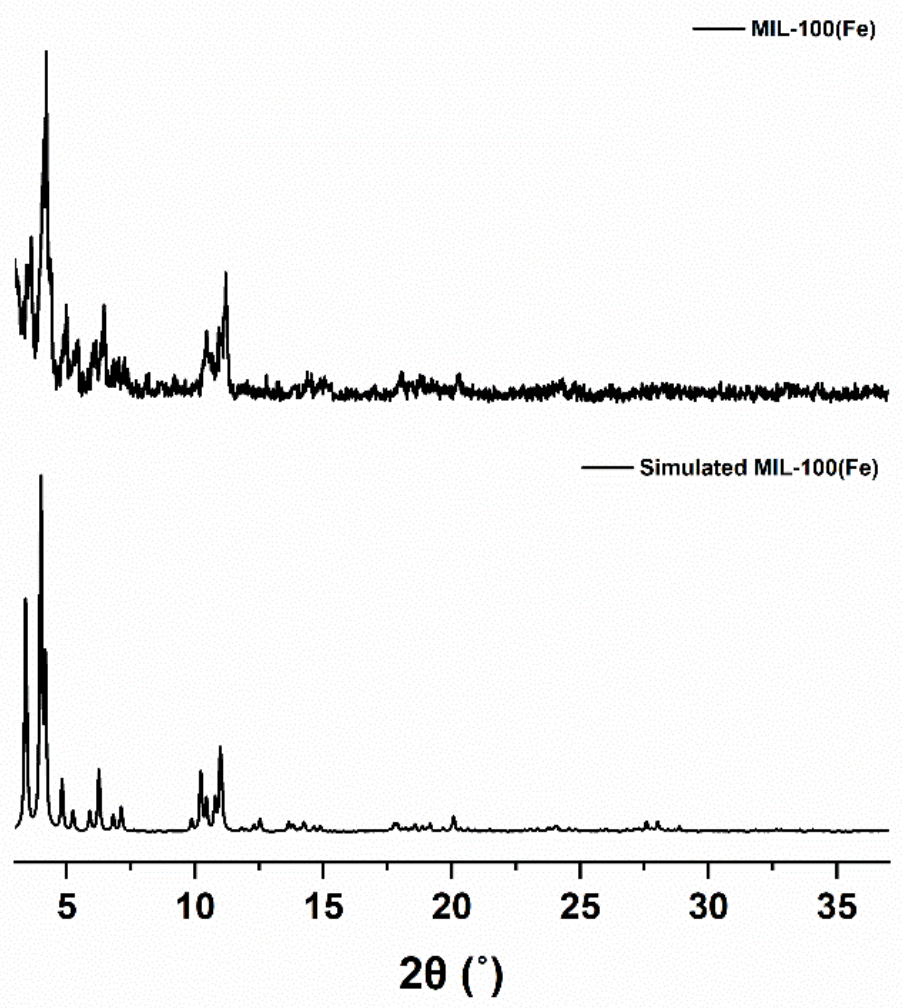

Figure S4. Powder X-ray diffraction (PXRD) of MIL-100(Fe), which is commercially purchased (KRICT F100). PXRD pattern of MIL-100(Fe) was matched well with simulated MIL-100(Fe). 


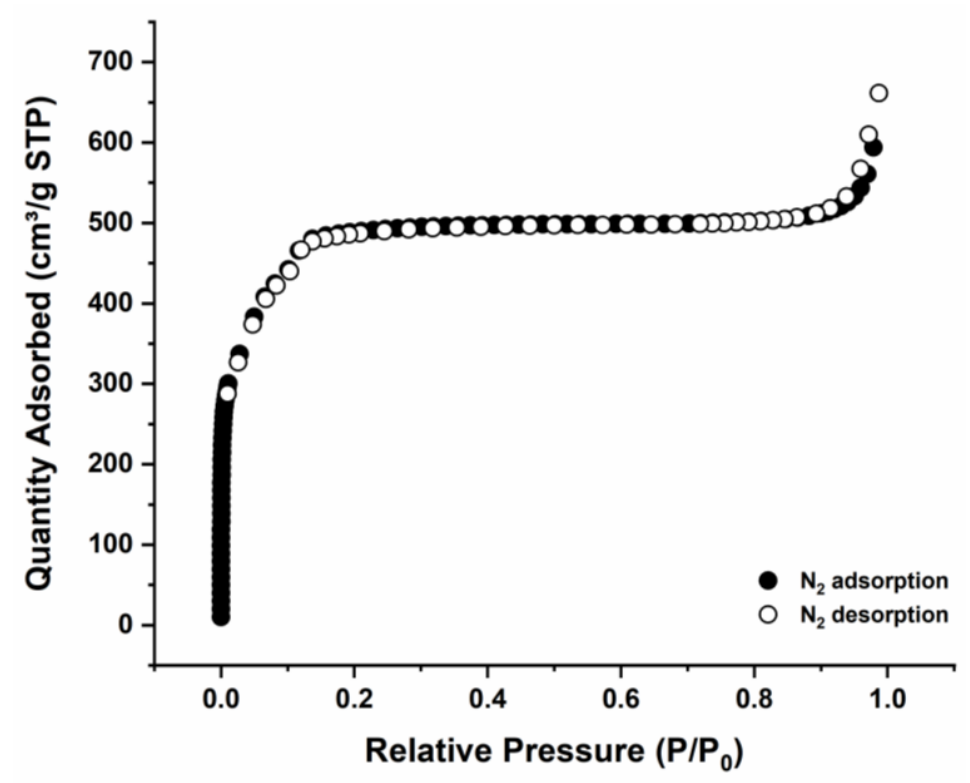

Figure S5. $\mathrm{N}_{2}$ sorption of MIL-100(Fe) at $77 \mathrm{~K} . \mathrm{N}_{2}$ sorption was conducted using an activated sample (activation: $150^{\circ} \mathrm{C}, 6 \mathrm{hrs}$ ). BET surface area is $1919 \mathrm{~m}^{2} \mathrm{~g}^{-1}$ and Langmuir surface area is $2194 \mathrm{~m}^{2} \mathrm{~g}^{-1}$. 
a

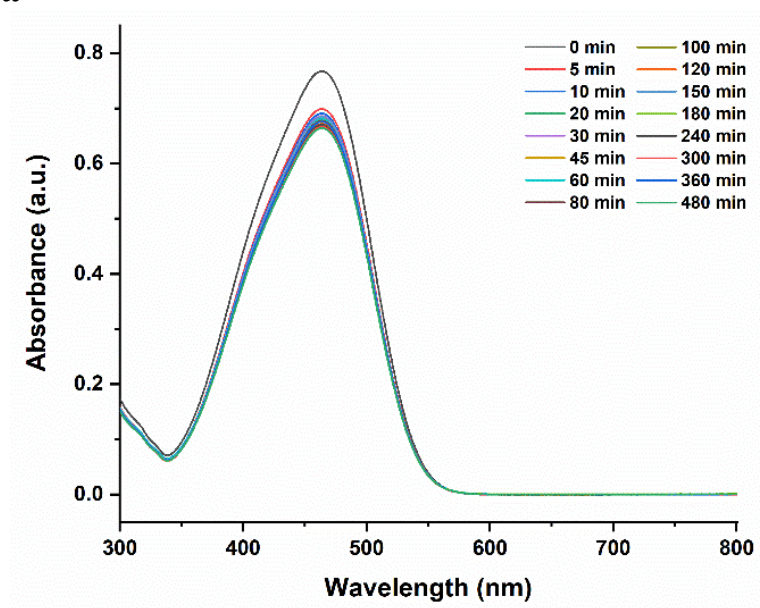

b

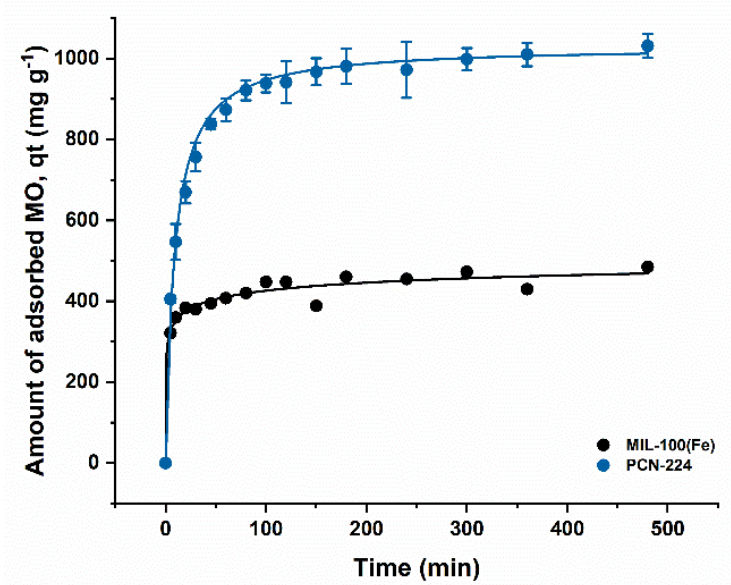

Figure S6. Dye adsorption of MIL-100(Fe). (a) UV-vis spectrum of MO adsorption onto MIL-100(Fe) during different times in an $80 \mathrm{~mL}$ of dye solution containing $20 \mathrm{mg}$ of MIL-100(Fe), which is activated during $12 \mathrm{hrs}$ at $120{ }^{\circ} \mathrm{C}$. (b) Adsorption capacity of MO onto MIL-100(Fe) and PCN-224 at $900 \mathrm{mg} \mathrm{L}-$ ${ }^{1}$ concentration. 
Table S4. The maximum number of MO molecules per unitcell of various MOFs.

\begin{tabular}{|c|c|c|c|c|c|c|c|}
\hline Complex & g / Cell & $\begin{array}{c}\text { Cell } \\
\text { Volume } \\
\left(\AA^{3}\right)\end{array}$ & $\begin{array}{c}\mathbf{A S V}^{a} \\
\left(\AA^{3}\right)\end{array}$ & $\begin{array}{c}\mathrm{qe}^{b} \\
(\mathrm{mg} / \mathrm{g})\end{array}$ & $\begin{array}{c}\text { \# of MO } \\
\text { (theoretical) }\end{array}$ & $\begin{array}{c}\# \text { of MO } \\
\text { (experiment) }\end{array}$ & Ref \\
\hline PCN-224 & 16355 & 56911 & 27929 & 1043(29) & 60 & 52 & This work \\
\hline MIL-100(Fe) & 292496 & 394481 & 142350 & 484 & 305 & 432 & This work \\
\hline PCN-222 & 7167 & 26149 & 13464 & 589 & 29 & 13 & 25 \\
\hline PCN-222(Fe) & 7715 & 26149 & 13464 & 380 & 29 & 9.0 & 26 \\
\hline MIL-100(Fe) & 292496 & 394481 & 142350 & 1045 & 305 & 934 & 27 \\
\hline
\end{tabular}


3. Interactions between PCN-224 and MO molecule

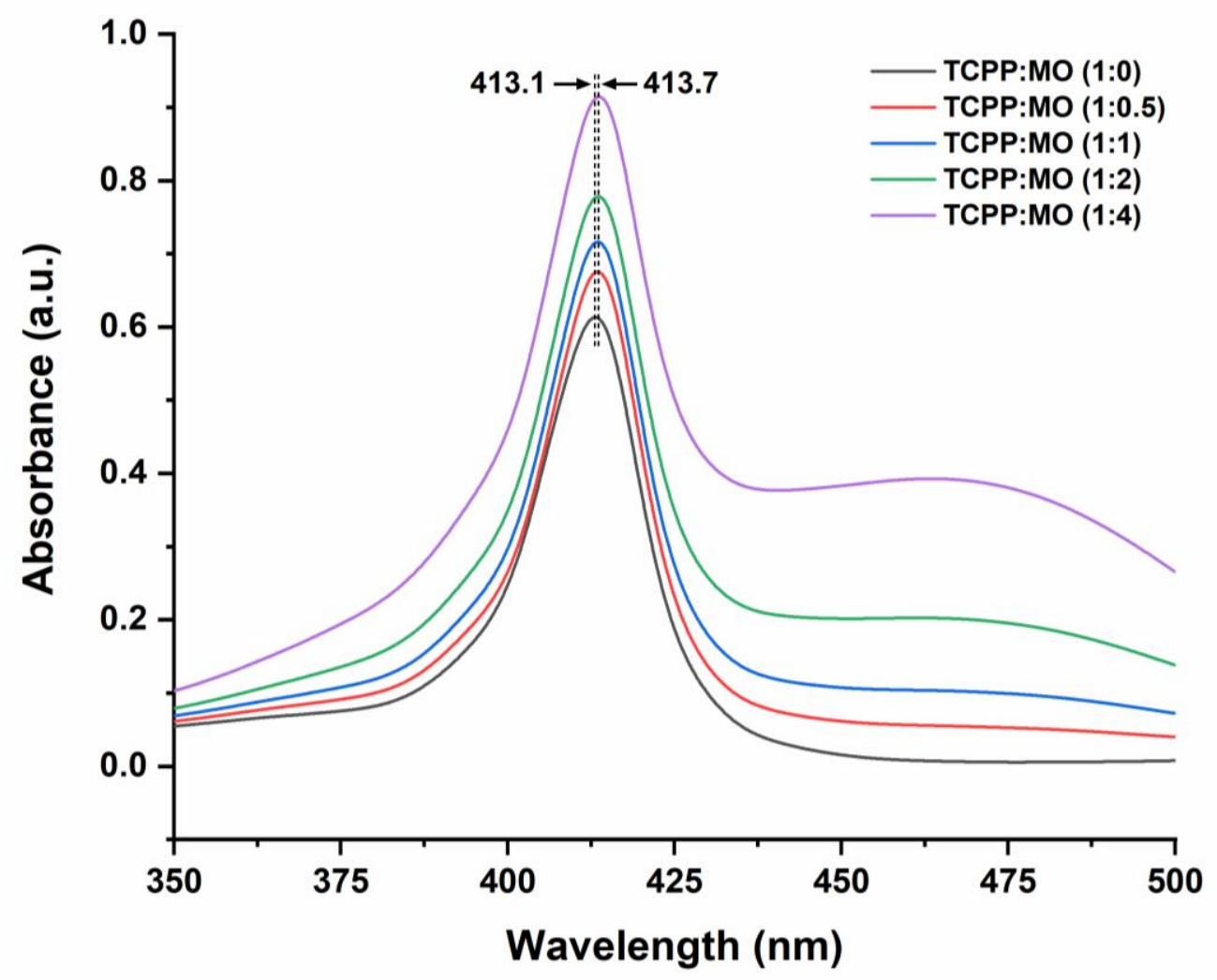

Figure S7. The $\pi-\pi$ interaction between methyl orange and TCPP. UV-vis spectra of TCPP and TCPP:MO. 


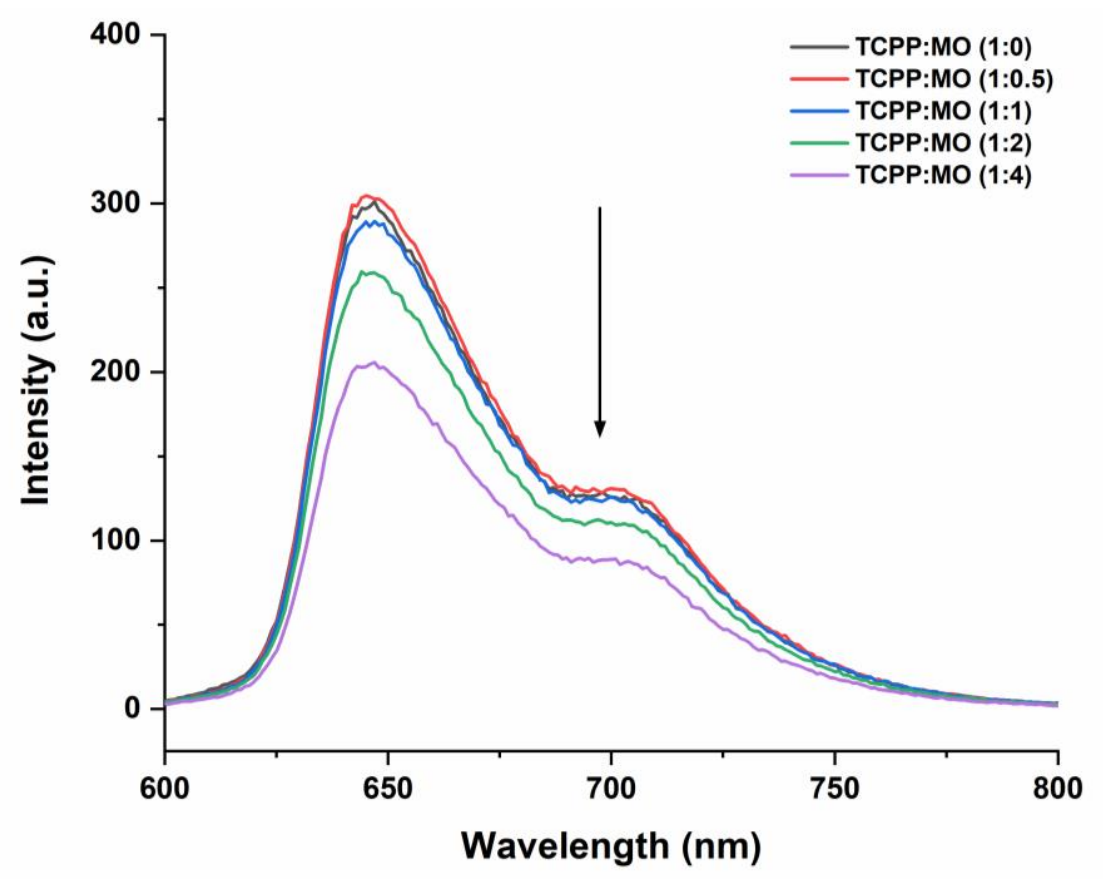

Figure S8. Fluorescence spectra of TCPP depending on MO concentrations. The quenched intensity of TCPP demonstrates the $\pi-\pi$ interaction between methyl orange and TCPP (Excitation: $420 \mathrm{~nm}$ ). 

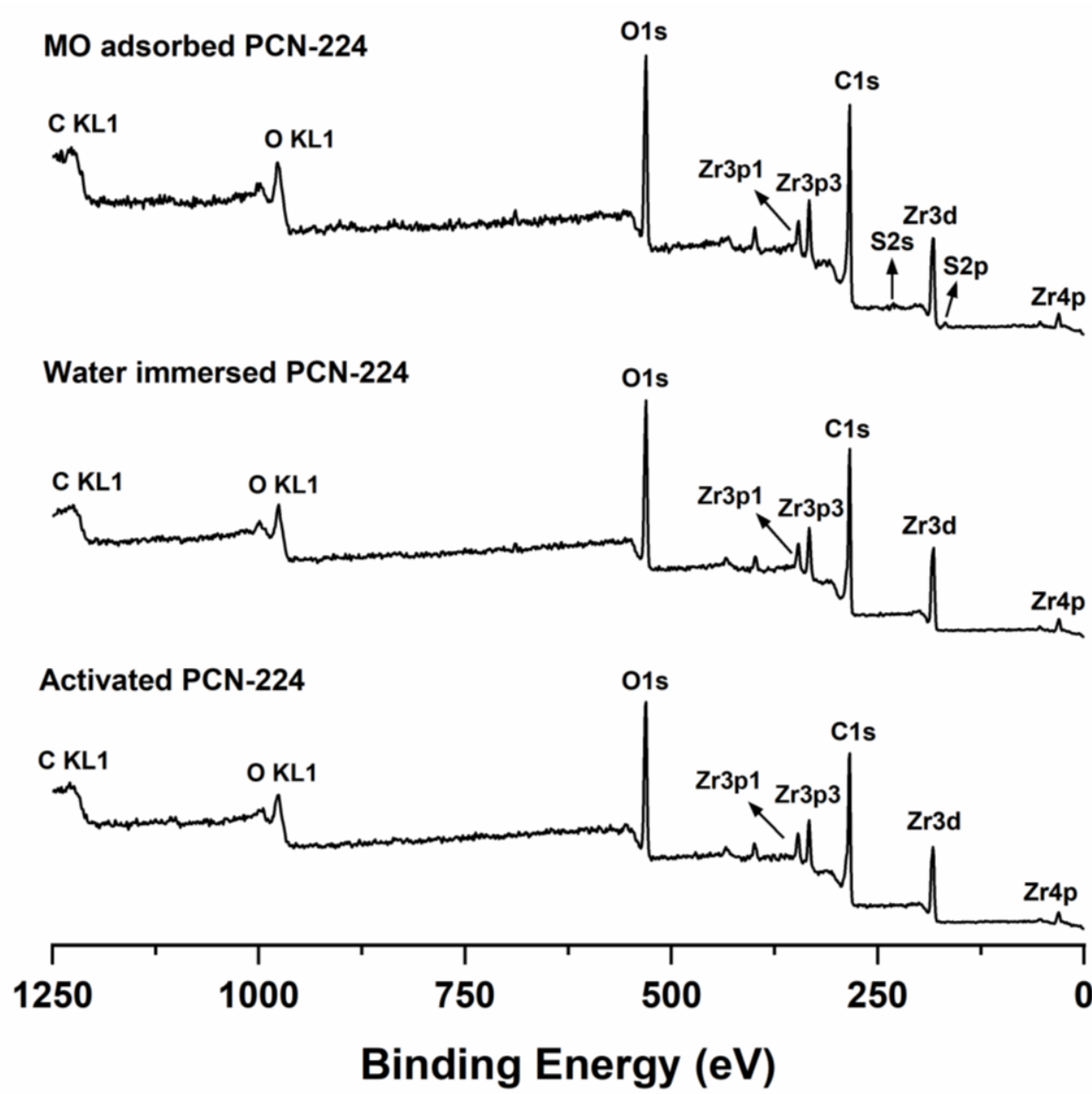

Figure S9. Survey XPS spectra of (a) activated PCN-224 and (b) water immersed PCN-224 (b) MO adsorbed PCN-224. After MO adsorption, S2s and S2p electrons of MO molecule appear in the XPS spectrum of MO adsorbed PCN-224. 


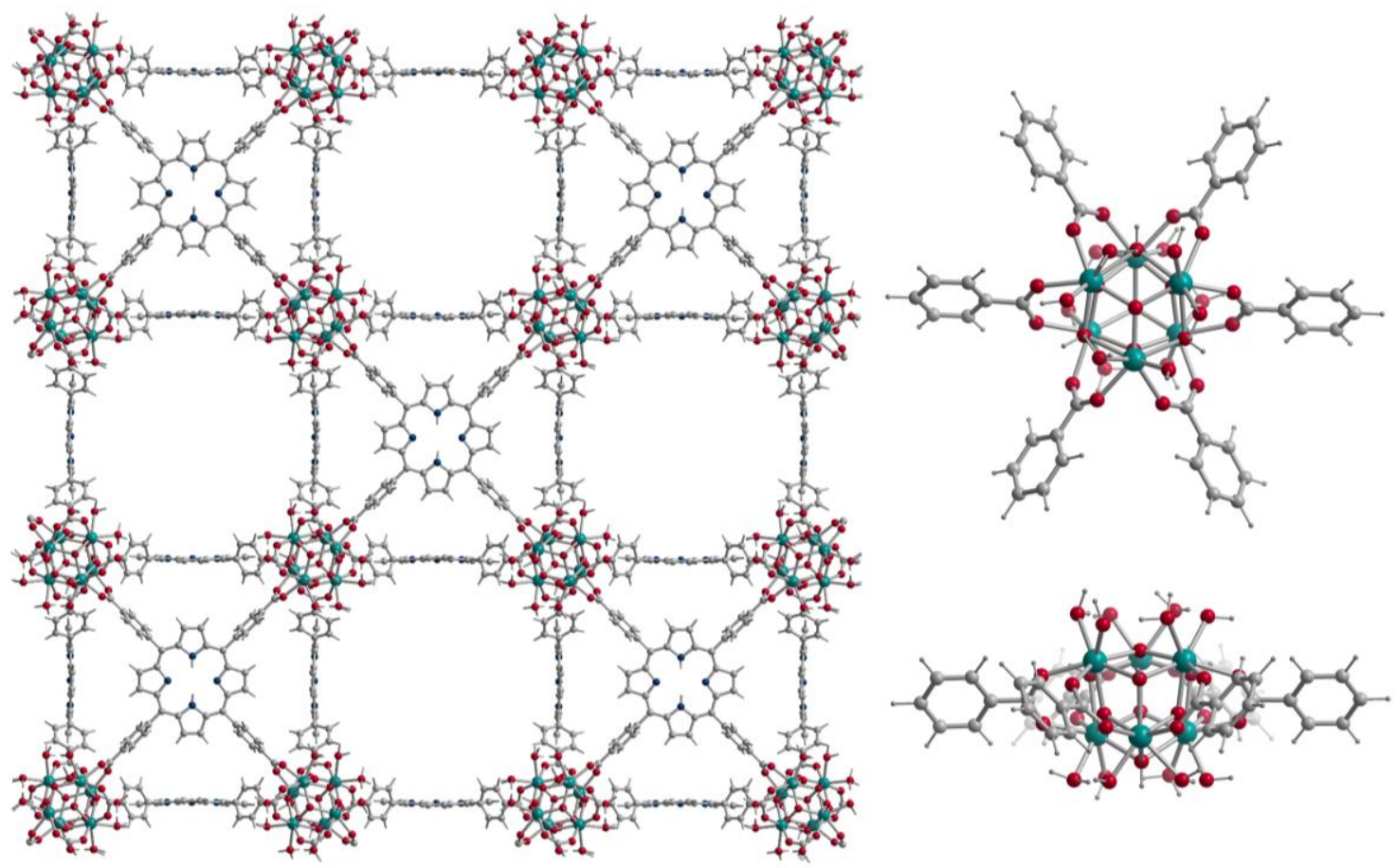

Figure S10. Adsorptive sites of PCN-224 through simulation. Truncated molecular fragments of $\mathrm{Zr}_{6}$ node in the optimized periodic structure. 


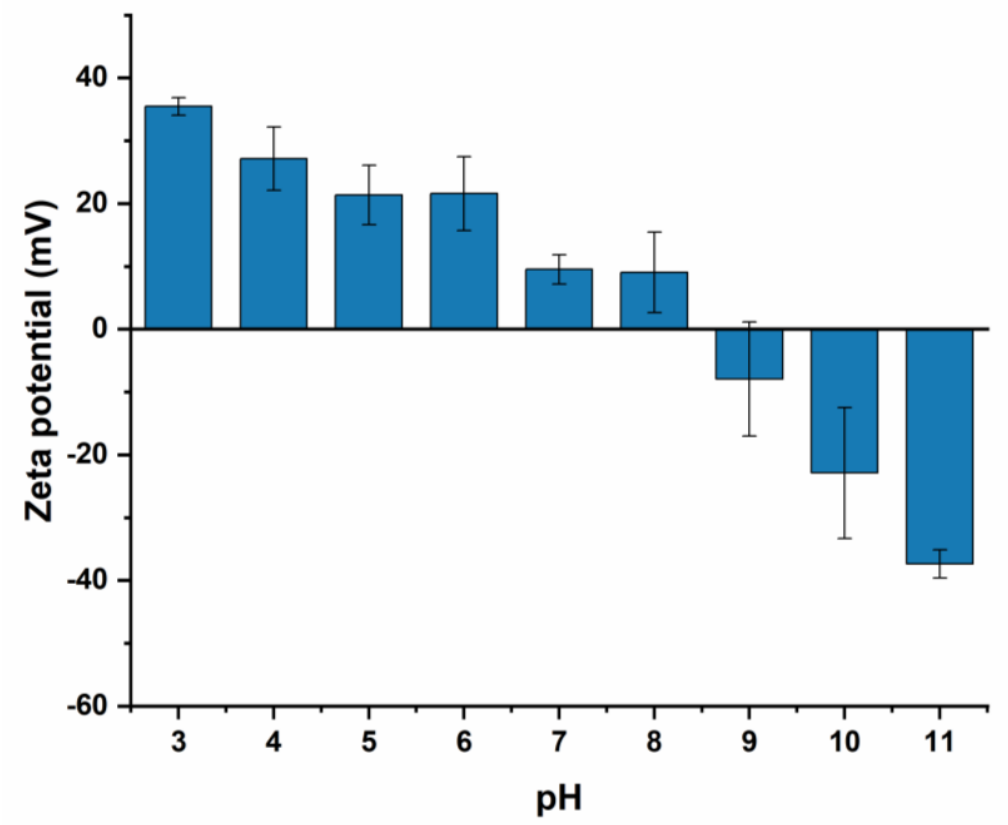

Figure S11. Zeta potential of PCN-224 in a wide range of $\mathrm{pH}$ solutions from 3 to 11 . The $\mathrm{pH}$ values of each solution were adjusted using $\mathrm{HCl}$ or $\mathrm{NaOH}$. 


\section{References}

(1) Feng, D.; Chung, W.-C.; Wei, Z.; Gu, Z.-Y.; Jiang, H.-L.; Chen, Y.-P.; Darensbourg, D. J.; Zhou, H.-C. Construction of Ultrastable Porphyrin Zr Metal-Organic Frameworks through Linker Elimination. J. Am. Chem. Soc. 2013, 135, 17105-17110.

(2) Yang, J.; Wang, Z.; Hu, K.; Li, Y.; Feng, J.; Shi, J.; Gu, J. Rapid and specific aqueousphase detection of nitroaromatic explosives with inherent porphyrin recognition sites in metal-organic frameworks. ACS Appl. Mater. Interfaces 2015, 7, 11956-11964.

(3) Shi, L.; Yang, L.; Zhang, H.; Chang, K.; Zhao, G.; Kako, T.; Ye, J. Implantation of iron (III) in porphyrinic metal organic frameworks for highly improved photocatalytic performance. Appl. Catal. B 2018, 224, 60-68.

(4) Hintz, H.; Wuttke, S. Solvent-free and time efficient postsynthetic modification of aminotagged metal-organic frameworks with carboxylic acid derivatives. Chem. Mater. 2014, $26,6722-6728$.

(5) Ho, Y. S.; Mckay, G. A comparison of chemisorption kinetic models applied to pollutant removal on various sorbents. Process Saf. Environ. Prot. 1998, 76, 332-340.

(6) El-Khaiary, M. I.; Malash, G. F.; Ho, Y. S. On the use of linearized pseudo-second-order kinetic equations for modeling adsorption systems. Desalination 2010, 257, 93-101.

(7) Langmuir, I. The adsorption of gases on plane surfaces of glass, mica and platinum. $J$. Am. Chem. Soc. 1918, 40, 1361-1403.

(8) Frendlich, H. M. F. Over the adsorption in solution. J. Phy. Chem. 1906, 57, 385-470.

(9) Weber, W. J.; Morris, J. C. Kinetics of adsorption on carbon from solution. J. Sanit. Eng. Div. Am. Soc. Civ. Eng. 1963, 89, 31-39.

(10) Mendonca, M. L.; Ray, D.; Cramer, C. J.; Snurr, R. Q. Exploring the effects of node topology, connectivity, and metal identity on the binding of nerve agents and their hydrolysis products in metal-organic frameworks. ACS Appl. Mater. Interfaces 2020, 12, 35657-35675.

(11) Kresse, G.; Furthmüller, J. Efficiency of ab-initio total energy calculations for metals and semiconductors using a plane-wave basis set. Comput. Mater. Sci. 1996, 6, 15-50.

(12) Kresse, G.; Furthmüller, J. Efficient iterative schemes for ab initio total-energy calculations using a plane-wave basis set. Phys. Rev. B 1996, 54, 11169-11186.

(13) Kresse, G.; Joubert, D. From ultrasoft pseudopotentials to the projector augmented-wave method. Phys. Rev. B 1999, 59, 1758-1775. 
(14) Perdew, J. P.; Wang, Y. Accurate and simple analytic representation of the electron-gas correlation energy. Phys. Rev. B 1992, 45, 13244-13249.

(15) Perdew, J. P.; Burke, K.; Ernzerhof, M. Generalized gradient approximation made simple. Phys. Rev. Lett. 1996, 77, 3865-3868.

(16) Grimme, S.; Antony, J.; Ehrlich, S.; Krieg, H. A consistent and accurate ab initio parametrization of density functional dispersion correction (DFT-D) for the 94 elements H-Pu. J. Chem. Phys. 2010, 132, 154104.

(17) Johnson, E. R.; Becke, A. D. A post-Hartree-Fock model of intermolecular interactions. J. Chem. Phys. 2005, 123, 024101.

(18) Becke, A. D.; Johnson, E. R. A density-functional model of the dispersion interaction. $J$. Chem. Phys. 2005, 123, 154101.

(19) Johnson, E. R.; Becke, A. D. A post-Hartree-Fock model of intermolecular interactions: Inclusion of higher-order corrections. J. Chem. Phys. 2006, 124, 174104.

(20) Grimme, S.; Ehrlich, S.; Goerigk, L. Effect of the damping function in dispersion corrected density functional theory. J. Comput. Chem. 2011, 32, 1456-1465.

(21) Weigend, F.; Ahlrichs, R. Balanced basis sets of split valence, triple zeta valence and quadruple zeta valence quality for $\mathrm{H}$ to Rn: Design and assessment of accuracy. Phys. Chem. Chem. Phys. 2005, 7, 3297-3305.

(22) Andrae, D.; Häußermann, U.; Dolg, M.; Stoll, H.; Preuß, H. Energy-adjusted ab initio pseudopotentials for the second and third row transition elements. Theoret. Chim. Acta 1990, 77, 123-141.

(23) Frisch, M. J.; Trucks, G. W.; Schlegel, H. B.; Scuseria, G. E.; Robb, M. A.; Cheeseman, J. R.; Scalmani, G.; Barone, V.; Petersson, G. A.; Nakatsuji, H.; Li, X.; Caricato, M.; Marenich, A. V.; Bloino, J.; Janesko, B. G.; Gomperts, R.; Mennucci, B.; Hratchian, H. P.; Ortiz, J. V.; Izmaylov, A. F.; Sonnenberg, J. L.; Williams-Young, D.; Ding, F.; Lipparini, F.; Egidi, F.; Goings, J.; Peng, B.; Petrone, A.; Henderson, T.; Ranasinghe, D.; Zakrzewski, V. G.; Gao, J.; Rega, N.; Zheng, G.; Liang, W.; Hada, M.; Ehara, M.; Toyota, K.; Fukuda, R.; Hasegawa, J.; Ishida, M.; Nakajima, T.; Honda, Y.; Kitao, O.; Nakai, H.; Vreven, T.; Throssell, K.; Montgomery, J. A., Jr.; Peralta, J. E.; Ogliaro, F.; Bearpark, M. J.; Heyd, J. J.; Brothers, E. N.; Kudin, K. N.; Staroverov, V. N.; Keith, T. A.; Kobayashi, R.; Normand, J.; Raghavachari, K.; Rendell, A. P.; Burant, J. C.; Iyengar, S. S.; Tomasi, J.; Cossi, M.; Millam, J. M.; Klene, M.; Adamo, C.; Cammi, R.; Ochterski, J. W.; Martin, R. L.; Morokuma, K; Farkas, O.; Foresman, J. B.; Fox, D. J. Gaussian 16, Revision C.01; Gaussian Inc.: Wallingford CT, 2016. 
(24) Lipparini, F.; Scalmani, G.; Mennucci, B.; Cancès, E.; Caricato, M.; Frisch, M. J. Ayariational formulation of the polarizable continuum model. J. Chem. Phys. 2010, 133, 014106.

(25) Li, H.; Cao, X.; Zhang, C.; Yu, Q.; Zhao, Z.; Niu, X.; Sun, X.; Liu, Y.; Ma, L.; Li, Z. Enhanced adsorptive removal of anionic and cationic dyes from single or mixed dye solutions using MOF PCN-222. RSC Adv. 2017, 7, 16273-16281.

(26) Sarker, M.; Shin, S.; Jeong, J. H.; Jhung, S. H. Mesoporous metal-organic framework PCN-222(Fe): Promising adsorbent for removal of big anionic and cationic dyes from water. Chem. Eng. J. 2019, 371, 252-259.

(27) Tong, M.; Liu, D.; Yang, Q.; Devautour-Vinot, S.; Maurin, G.; Zhong, C. Influence of framework metal ions on the dye capture behavior of MIL-100 (Fe, Cr) MOF type solids. J. Mater. Chem. A 2013, 1, 8534-8537.

(28) Yi, F.-Y.; Li, J.-P.; Wu, D.; Sun, Z.-M. A series of multifunctional metal-organic frameworks showing excellent luminescent sensing, sensitization, and adsorbent abilities. Chem. Eur. J. 2015, 21, 11475-11482.

(29) Yang, J.-M. A facile approach to fabricate an immobilized-phosphate zirconium-based metal-organic framework composite (UiO-66-P) and its activity in the adsorption and separation of organic dyes. J. Colloid Interface Sci. 2017, 505, 178-185.

(30) Haque, E.; Lee, J. E.; Jang, I. T.; Hwang, Y. K.; Chang, J.-; Jegal, J.; Jhung, S. H. Adsorptive removal of methyl orange from aqueous solution with metal-organic frameworks, porous chromium-benzenedicarboxylates. J. Hazard. Mater. 2010, 181, $535-542$.

(31) Shen, T.; Luo, J.; Zhang, S.; Luo, X. Hierarchically mesostructured MIL-101 metalorganic frameworks with different mineralizing agents for adsorptive removal of methyl orange and methylene blue from aqueous solution. J. Environ. Chem. Engineer. 2015, 3, $1372-1383$.

(32) Haque, E.; Jun, J. W.; Jhung, S. H. Adsorptive removal of methyl orange and methylene blue from aqueous solution with a metal-organic framework materials, iron terephthalate (MOF-235). J. Hazard. Mater. 2011, 185, 507-611.

(33) Yang, J.-M.; Ying, R.-J.; Han, C.-X.; Hu, Q.-T.; Xu, H.-M.; Li, J.-H.; Wang, Q.; Zhang, W. Adsorptive removal of organic dyes from aqueous solution by a Zr-based metalorganic framework: effects of Ce(III) doping. Dalton Trans., 2018, 47, 3913-3920.

(34) Yang, J.-M.; Yang, B.-C.; Zhang, Y.; Yang, R.-N.; Ji, S.-S.; Wang, Q.; Quan, S.; Zhang, R.-Z. Rapid adsorptive removal of cationic and anionic dyes from aqueous solution by a 
Ce(III) doped Zr-based metal-organic framework. Micro. Meso. Mater. 2020, 292, 109764.

(35) Wu, S.-c.; You, X.; Yang, C.; Cheng, J.-h. Adsorption behavior of methyl orange onto an aluminum-based metal organic framework, MIL-68(Al). Water Sci. Technol. 2017, 75, $2800-2810$.

(36) Haque, E.; Lo, V.; Minett, A. I.; Harris, A. T.; Church, T. L. Dichotomous adsorption behaviour of dyes on an amino-functionalised metal-organic framework, amino-MIL101(Al). J. Mater. Chem. A, 2014, 2, 193.

(37) Zhang, C.; Li, H.; Li, C.; Li, Z. Fe-loaded MOF-545(Fe): Peroxidase-like activity for dye degradation dyes and high adsorption for the removal of dyes from wastewater. Molecules 2020, 25,168 .

(38) Wang, G.-Q.; Huang, J.-F.; Huang, X.-F.; Deng, S.-Q.; Zheng, S.-R.; Cai, S.-L.; Fan, J.; Zhang, W.-G. A hydrolytically stable cage-based metal-organic framework containing two types of building blocks for the adsorption of iodine and dyes. Inorg. Chem. Front. 2021, 8, 1083.

(39) Huang, L.; He, M.; Chen, B.; Hu, B. Magnetic Zr-MOFs nanocomposites for rapid removal of heavy metal ions and dyes from water. Chemosphere 2018, 199, 435-444.

(40) Lv, S.-W.; Liu, J.-M.; Ma, H.; Wang, Z.-H.; Li, C.-Y.; Zhao, N.; Wang, S. Simultaneous adsorption of methyl orange and methylene blue from aqueous solution using amino functionalized Zr-based MOFs. Micro. Meso. Mater. 2019, 282, 179-187. 